This is a self-archived version of an original article. This version may differ from the original in pagination and typographic details.

Author(s): Kari, Tuomas; Makkonen, Markus; Frank, Lauri; Kettunen, Eeva

Title: Expectations and Experiences of Implementing a Mobile Secure Communication Application

Year: 2020

Version: Published version

Copyright: (c) 2020, IGI Global.

Rights: In Copyright

Rights url: http://rightsstatements.org/page//nC/1.0/?language=en

Please cite the original version:

Kari, T., Makkonen, M., Frank, L., \& Kettunen, E. (2020). Expectations and Experiences of Implementing a Mobile Secure Communication Application. International Journal of E-Services and Mobile Applications, 12(1), 80-96. https://doi.org/10.4018/IJESMA.2020010105 


\title{
Expectations and Experiences of Implementing a Mobile Secure Communication Application
}

\author{
Tuomas Kari, University of Jyvaskyla, Jyvaskyla, Finland \\ Markus Makkonen, University of Jyvaskyla, Jyvaskyla, Finland \\ (iD) https://orcid.org/0000-0002-1553-211X \\ Lauri Frank, University of Jyvaskyla, Jyvaskyla, Finland \\ Eeva Kettunen, University of Jyvaskyla, Jyvaskyla, Finland
}

\begin{abstract}
The privacy and security of communication in corporations and governmental organizations has increased enormously over the years. At the same time, a growing amount of technological solutions to support this have emerged. This study examines user expectations before and use experiences during the implementation phase of a mobile secure communication application. These are investigated from the expectation-confirmation perspective and its influence on continued adoption. The study has an exploratory approach for this investigation. To guide the investigation, the study draws from the expectation-confirmation theory (ECT) and the unified theory of acceptance and use of technology (UTAUT). Empirically, the study is qualitative and conducted in a governmental organization in Finland. The findings reveal the key user expectations and use experiences and their importance for users in terms of implementation and continued adoption of a mobile secure communication application.
\end{abstract}

\section{KEYWORDS}

Acceptance, Adoption, Implementation, Mobile Application, Organizational Context Privacy, Secure Communication, Security, Use Experience, User Expectations

\section{INTRODUCTION}

In the increasingly digital world of today, the majority of communication takes place through different digital communication channels. As people are more and more "on the move" or otherwise remotely located, the popularity and importance of different ubiquitous communication devices has exploded. This is the case in corporate, governmental, military, and personal use alike. Moreover, many things that need to be communicated contain information that is confidential or otherwise meant for certain eyes and ears only, such as, trade secrets, state secrets, or information that is otherwise sensitive or confidential. Naturally, this information can also be of interest to certain outsiders, such as industry competitors, foreign governments, or criminals. It is well known that the attempts and attacks to capture confidential information are common and increasing all the time. More and more of these attempts and attacks are also targeting mobile devices (Trend Micro, 2017). Therefore, there is a growing need, especially in corporations and governmental organizations, to ensure that critical 
communication is safe and secure and the confidentiality of information is not breached. Indeed, corporations and organizations have paid an increasing consideration to information systems (IS) security and privacy during the past years. To decrease the risk posed by the prevalent security and privacy threats, different solutions have emerged to safeguard the confidentiality of communication. Some of the solutions, such as e-mail encryption software, have been around for a long time, but also more novel solutions exist. These include, for example, mobile applications meant for communication in corporations and organizations in cases where secure and confidential communication is essential.

Security and privacy management in the area of mobile communication has been studied since the early 1990s (Chan, Kwong, \& Longginnou, 1993). The whole research stream of IS security and privacy dates back to the beginning of the 1970s (Bates, 1970) and has focused on various approaches and topics around security and privacy issues. Over the years, also several reviews on IS security research have been published (e.g., Baskerville, 1993; Cram, Proudfoot, \& D'Arcy, 2017; Dhillon \& Backhouse, 2001; Guo, 2013; Siponen \& Oinas-Kukkonen, 2007; Sommestad, Hallberg, Lundholm, \& Bengtsson, 2014; Soomro, Shah, \& Ahmed, 2016; Willison \& Siponen, 2007), which illustrate the development of the topics and the central issues under research. Yet, as the technology, means, and needs of communication and the regarding security and privacy threats advance and are constantly evolving, there is an eminent need to keep IS security research in line with the most novel technologies.

To date, studies focusing on mobile secure communication applications for organizational use are few, and most of them have focused on the technical side. However, user-centric studies on use, use experience, and acceptance aspects of mobile services have been conducted. For example, Carlsson, Carlsson, Hyvönen, Puhakainen, and Walden (2006) examined the acceptance of personal mobile devices and services in general and found, among others, that effort expectancy, performance expectancy, and attitude influence use intention, which in turn influences the actual use of mobile devices and services. Lee, Hwang, and Kwon (2015) investigated how the perceptions of a (nonsecure) mobile instant messenger affect its continued use intention in an organizational setting through perceived usefulness. They found, for example, that perceived enjoyment has a positive effect on perceived usefulness, that perceived usefulness has a positive effect on satisfaction and the continued use intention of a mobile instant messenger, and that expectation-confirmation has a positive effect on perceived usefulness. Pham, Pham, Brennan, and Richardson (2017) investigated end-users' and IT managers' attitudes towards performing IT security tasks and suggested that in order to enhance the probability of end-users internalizing security requirements, the regulatory processes need to shift from a mere compliance (other-directed) towards interest, enjoyment, and inherent satisfaction (self-directed). Overall, the need to deepen the user-centric research is eminent.

Security and privacy are at the forefront of mobile application usage, and the need for secure communication solutions is prevalent. As the demand and importance for secure communication in corporations and governmental organizations is increasing and the solutions to meet this are used more and more, the use of technologies providing the means for secure communication become an increasingly relevant topic to be studied. Thus, it is important to study the use experiences and to find out what kind of experiences either promote or hinder the use of these technologies. After all, technological systems can only be useful if people use them (Mathieson, 1991). Examining the use experiences provides important information about the reasons of use, adoption, and non-adoption. Understanding these reasons, and especially those related to innovation resistance, is essential because the main reason to use such technologies is typically to secure the important information of an organization, corporation, or nation. Despite the varying aspects of IS research on mobile security and privacy, there is limited research on how users adopt and experience the relatively novel mobile applications for secure communication. Studying such issues can have several important implications for the development and diffusion of these technologies as well as for implementing them into use in different kinds of organizations.

The purpose of this study is to address the aforementioned gap by qualitatively exploring the expectations that users have towards mobile secure communication applications before the 
implementation phase and how the (dis)confirmation of these user expectations through the use experiences during the implementation phase influences the continued adoption or discontinuance of the applications. The study aims to contribute by answering the following research questions:

1. What are the key expectations that users have towards mobile secure communication applications before the implementation phase?

2. How does the (dis)confirmation of these user expectations through the use experiences during the implementation phase influence the users' continued adoption or discontinuance of mobile secure communication applications?

The study is exploratory in nature and follows a qualitative approach. The emphasis of the study is on an organizational setting, and it focuses on the experiences and continued adoption during the implementation phase. The implementation phase is set to cover the first 12 weeks of use, which was seen as a sufficient time period for users to be able to (dis)confirm their expectations based on their use experiences. Empirically, the study is based on a thematic analysis of the data collected from the pilot users of a mobile secure communication application who work in a governmental organization in Finland.

This study deepens the understanding of user expectations and use experiences with mobile secure communication applications. The findings can be utilized by corporate and governmental actors when implementing secure communication solutions in their organizations. In addition, the findings can aid the industry to develop better mobile applications and other solutions for secure communication, which are better welcomed by the users and gain more success in the market, thus promoting their adoption and diffusion.

The rest of the paper is organized as follows. After this introduction, the theoretical background of the study is described, followed by the methodology, findings, and discussion. Finally, the limitations and potential paths for future research are briefly discussed.

\section{BACKGROUND}

In technology adoption, when searching for appropriate solutions and testing different options to meet the prevalent needs, the implementation phase is crucial: Does the new technology bring enough added value or not (Rogers, 2003)? Rogers (2003, p. 475) defines the implementation phase in the innovation diffusion theory as a phase of the innovation-decision process where the individual implements the innovation into use and determines its usefulness. Following the initial adoption decision, and based on the implementation phase, the individual then makes the final adoption decision, that is, decides whether to continue using the innovation (continued adoption) or whether to reject the innovation (discontinuance). Hence, the implementation phase is perhaps the most essential phase in the innovation-decision process and imperative to study when examining the adoption of an innovation and the use experiences that influence its continued adoption or discontinuance. Therefore, this study focuses on the implementation phase and the user experiences during it instead of the longer-term use.

This study and the idea that (dis)confirmation of expectations influences behavioral intention (in this case, continued adoption or discontinuance) derives from the expectation-confirmation theory (ECT) by Oliver $(1977 ; 1980)$. To guide the investigation of which expectations are the most central regarding the use of mobile secure communication applications, or IS in general, this study draws from the unified theory of acceptance and use of technology (UTAUT) by Venkatesh, Morris, Davis, and Davis (2003). It is to be noted that the aim of the study is not to confirmatory test either of these theories but rather to use them as theoretical lenses in this exploratory research and in guiding the data collection and analysis.

The ECT (illustrated in Figure 1) posits that expectations, together with perceived performance, affect use satisfaction. This effect is mediated by the positive or negative disconfirmation of the 
expectations and performance. If the perceived performance of a product or a service is greater than the expectation (positive disconfirmation), it will result in satisfaction. In contrast, if the perceived performance is less than the expectation (negative disconfirmation), it will result in dissatisfaction. Additionally, the ECT posits that perceived performance directly affects satisfaction (Oliver, 1980). Finally, satisfaction influences (behavioral) intention. In the ECT, expectations refer to the features an individual expects from a product or a service and its use before using it, for example, the expected benefits of mobile application use. Perceived performance refers to an individual's perceptions of the actual performance of a product or a service, which are formed based on the use experiences. (Dis) confirmation of the expectations refers to the evaluations that an individual makes regarding a product or a service. Satisfaction refers to an individual's degree of satisfaction with a product or a service after having direct use experiences with it. In other words, the ECT posits that the expectations towards a product or a service, and how the use of it meets these expectations, will influence use satisfaction. This, in turn, influences (behavioral) intention in terms of use continuance or discontinuance.

The ECT has previously been applied in IS research, for example, in the expectation-confirmation model (Bhattacherjee, 2001) and the expanded two-stage model of IS continuance (Venkatesh, Thong, Chan, Hu, \& Brown, 2011). These theories hold the same idea with the ECT. That is, the (dis)confirmation of expectations (among other determinants and mediators) influence behavioral intention. In the ECT, these expectations are not specified. Therefore, to guide the investigation into the expectations in this exploratory study, the study draws from the UTAUT, which posits that in the IS context, the expectations regarding performance expectancy, effort expectancy, social influence, and facilitating conditions are the main determinants of behavioral intention. As the UTAUT precisely focuses on technology acceptance in an organizational context (Venkatesh et al., 2003), this theoretical lens can be seen as highly suitable for this particular study.

Overall, the UTAUT has been widely applied in IS research (e.g., Venkatesh, Thong, \& Xu, 2016; Williams, Rana, \& Dwivedi, 2015). The authors of the original UTAUT paper presented their results quantitatively in order to empirically validate the theory. However, during the years, researchers have used the theory also qualitatively in order to gain a more in-depth understanding of the acceptance and use of technology (e.g., Kiwanuka, 2015; Williams, Rana, \& Dwivedi, 2012). In the UTAUT, Venkatesh et al. (2003) combined different determinants of technology acceptance and use into one unified model. The UTAUT has four core determinants of behavioral intention and use that affect the acceptance and use of technology: performance expectancy, effort expectancy, social influence, and facilitating conditions. Of these, the effects of the three former ones are mediated by behavioral intention, whereas the latter one affects use behavior directly. The UTAUT also presents four moderators of those key relationships: gender, age, experience, and the voluntariness of use (Venkatesh et al., 2003).

In the UTAUT (Venkatesh et al., 2003), performance expectancy refers to the degree to which an individual believes that using the system will help him or her to attain gains in job performance. Effort expectancy refers to the degree of ease associated with the use of the system. Social influence refers

Figure 1. Illustration of the expectation-confirmation theory (based on Oliver, 1977, 1980)

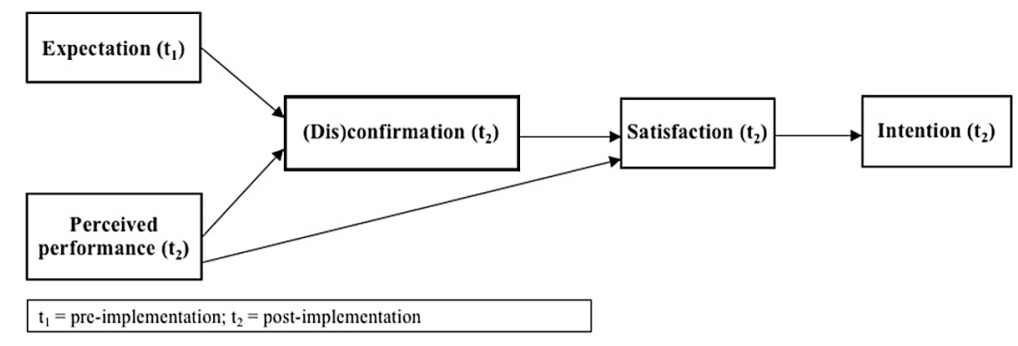


to the degree to which an individual perceives that important others believe he or she should use the new system. Facilitating conditions refers to the degree an individual believes that an organizational and technical infrastructure exists to support the use of the system (Venkatesh et al., 2003).

Later on, Venkatesh, Thong, and Xu (2012) extended the UTAUT and introduced the UTAUT2 to cover the context of individual consumers. The UTAUT2 introduced three new determinants of behavioral intention and use behavior into the original UTAUT: hedonic motivation, price value, and habit. Additionally, facilitating conditions are seen to affect also behavioral intention. Similar to the UTAUT, gender, age, and experience act as moderators of those key relationships, while the voluntariness of use was dropped from the model because consumer behaviors are typically voluntary (Venkatesh et al., 2012).

As mentioned, this study uses the UTAUT as a guide to aid the exploratory investigation of the key expectations. In addition to deriving from the determinants of the original UTAUT, this study also derives from the habit determinant of the UTAUT2. A similar approach, that is, drawing from the original UTAUT added with habit, has previously been used, for example, by Pahnila, Siponen, and Zheng (2011). Habit refers to the extent to which people tend to perform behaviors automatically because of learning (Limayem, Hirt, \& Cheung, 2007; Venkatesh et al., 2012). From the UTAUT2, hedonic motivation was not considered as the purpose of using mobile secure communication applications is primarily utilitarian. Also, price value was not considered as the use setting was organizational and the use was free for the users.

\section{METHODOLOGY}

To collect and analyze the user expectations before the implementation phase and the use experiences from the implementation phase, this study follows mainly a qualitative approach. Qualitative research aims to understand people, their sayings and doings, as well as the social and cultural context in which they act. The goal is to understand real life and find new knowledge. One of the key benefits of qualitative research is that it enables a researcher to see and understand the underlying contexts in which actions happen and decisions are made (Myers, 2013).

The study was conducted in cooperation with the provider of the mobile secure communication application and a Finnish governmental organization. The application provider provided the application for the governmental organization where 50 employees implemented it into use. The application was installed on their work phones, and all the 50 employees started using it at the same time. The focus of the study was on the implementation phase (a pilot period of 12 weeks). Most of the employees took part in the pilot voluntarily, while for some it was a part of specified work tasks. Typical for an organizational setting, in both cases, the idea of initial adoption came from the organization. The pilot took place during September-November 2017.

The governmental organization where the study took place was one of the many governing bodies in Finland. It had various central tasks related to state affairs and international affairs, such as coordinating, overseeing, and enacting governmental activities. The size of the organization was about 500 persons at the time the study was conducted. Secure communication was of critical importance in the organization, and the organization was looking for new and suitable solutions to support it.

The implemented application was described by its provider as a comprehensive solution for secure communication. The application was designed for actors who need to ensure the security and privacy of their communications. Its purpose was to protect the security and privacy of calls and messages. Some of its key features included, for example, strong authentication, strong voice and message encryption, a possibility for multiple encryption, a controlled life cycle of the messages, and a high-availability background system that is organization specific, scalable, and can be geographically decentralized. The application also worked on most modern mobile devices (Android or iOS). Because of these properties, it was an excellent case application for this particular study. 
To gather the data, different data collection methods were utilized. Two surveys that focused on gathering qualitative data with mainly open-ended questions were carried out - one before the start of the pilot and one right after the pilot had ended. The first survey (pre-implementation) focused on the user expectations towards the application, whereas the second survey (post-implementation) focused on the use experiences with the application as well as the behavioral intention regarding continued adoption or discontinuance. As the setting was organizational, the intention of continued adoption or discontinuance was enquired as the willingness to continue using the application after the pilot. The two surveys acted as the primary data source. In addition to these, as a secondary data source, the authors also conducted interviews at the end of the pilot period in order to deepen the data regarding the use experiences (collected with the second survey) and explain the use experiences more richly. Developing the themes of the surveys and interviews was based on previous literature and guided by the ECT and the UTAUT. The themes of the surveys and interviews are presented in the appendices.

The surveys were created by using the LimeSurvey 2.05+ software. Before the launch of the surveys, their questionnaires were discussed together with several IS experts and the application provider. These discussions resulted in a few minor modifications, which were made before the launch of the surveys. For the interviews, a semi-structured qualitative interview was chosen because the goal was to deepen the gathered data regarding the use experiences from the second survey. A semistructured interview is the most used type of interview in qualitative research in the IS field (Myers \& Newman, 2007). In a semi-structured interview, there is an incomplete script, but typically some pre-formed structure that the interviewer follows (Myers \& Newman, 2007). This was also the case in this study. In order to gain maximal benefit from using a semi-structured interview and avoid the potential problems and pitfalls, relevant guidelines for semi-structured interviews were followed in planning and conducting the interviews (Guest, Bunce, \& Johnson, 2006; Myers, 2013; Myers \& Newman, 2007). This included preparing an interview script for the interviews. Following Myers and Newman (2007), this script included an opening, an introduction, key questions related to certain themes, and the closing.

All of the 50 pilot participants were invited to respond to the surveys. Although not everyone did this, the surveys were still able to gather a sufficient amount of data through the open-ended questions. In addition to the survey data, five pilot participants were interviewed. The interviews were held face-to-face together with one of the authors and a representative of the application provider. On average, the interviews lasted for 70 minutes. The interviews were recorded and notes were written during them in order to provide accurate data for the analysis.

Thematic analysis was used for all the data. The data from the first survey was used for investigating the user expectations, whereas the data from the second survey and the interviews were used to investigate the use experiences. Thematic analysis is the most widely used method of analysis in qualitative research (Guest, MacQueen, \& Namey, 2012). It is a method for "identifying, analyzing, and reporting patterns (themes) within data" (Braun \& Clarke, 2006, p. 79). It organizes and describes the data set in rich detail and typically goes deeper by interpreting various aspects of the research topic (Braun \& Clarke, 2006). In addition to identifying, analyzing, and reporting the patterns in the data, the aim in this study was to interpret the specific characteristics and exceptions related to the topic of research. For doing the analysis, the guidelines by Patton (2002) as well as Braun and Clarke (2006) were used. As suggested (Braun \& Clarke, 2006; Patton, 2002), these guidelines were applied flexibly to fit the research questions and the data, and the analysis process was not a linear phase-tophase process but a recursive one moving back and forth between the different phases of the analysis. The analysis began by first familiarizing with the data and marking all the interesting features in it. It then continued with a search for recurring themes, which were then reviewed in relation to the data. To aid this, a spreadsheet software was used. The primary data collected with the surveys was analyzed first and then complemented by analyzing the secondary data collected with the interviews in order to deepen the findings. Finally, a report of the findings was produced. 


\section{FINDINGS}

The surveys were able to gather responses from 27 of the 50 pilot participants. Of the respondents, 23 were male and four were female. The mean age of the respondents was 46.4 years (SD 8.3 years). The notably greater number of male respondents was due to the higher number of males among the pilot participants. Regarding age, information on the mean age or the age distribution of all the employees in the governmental organization was not available. However, the respondents' age distribution seems to be quite representative of a typical governmental organization. A more detailed description of the survey respondents is found in Table 1 . The interviewees consisted of three male and two female participants, who were between 31 and 60 years of age.

We also enquired the pilot participants about their technological innovativeness in general. Almost all of them perceived themselves as relatively interested in new technological solutions and capable of adopting and using them. Approximately three out of four also had prior experience using similar kinds of solutions in the past. Out of them, around half believed that those experiences would influence the implementation of the application positively.

\section{Perceptions of Using the Application}

Out of the survey respondents, slightly less than two thirds stated to be willing to continue using the application after the pilot. That is, they opted for continued adoption. A bit more than one third stated to be willing to discontinue using the application after the pilot. That is, they opted for discontinuance. This goes in line with the proportion of respondents who stated that they had / had not perceived getting the expected benefits of using the application. Opting for continued adoption of the application was influenced by various types of use experiences during the implementation phase. In line with the ECT, the positive or negative (dis)confirmation of the user expectations, together with perceived performance, were important in regard to satisfaction and subsequent continuance intention. It is not within the authors' knowledge if the organization decided to continue the use of the application after the pilot or decided to continue the use only with employees willing to do so.

We also enquired about the attitude towards using the application by asking the respondents to rate their attitude towards the use by using a seven-point semantic differential scale ranging from -3 to +3 and consisting of bipolar adjective pairs. As suggested by Fishbein and Ajzen (2010), we aimed to capture the overall, instrumental, and experiential aspects of attitude. All the enquired aspects of attitude - instrumental (+1.13), experiential $(+0.88)$, and overall $(+1.25)$ - were on the positive

Table 1. Description of the survey respondents

\begin{tabular}{|c|c|c|}
\hline & $\mathbf{N}$ & $\%$ \\
\hline \multicolumn{3}{|c|}{ Gender } \\
\hline $\begin{array}{l}\text { Male } \\
\text { Female }\end{array}$ & $\begin{array}{l}23 \\
4\end{array}$ & $\begin{array}{l}85.2 \\
14.8\end{array}$ \\
\hline \multicolumn{3}{|c|}{ Age } \\
\hline $\begin{array}{l}31-40 \\
41-50 \\
51-60 \\
61-\end{array}$ & $\begin{array}{l}8 \\
9 \\
9 \\
1\end{array}$ & $\begin{array}{l}29.6 \\
33.3 \\
33.3 \\
3.7\end{array}$ \\
\hline \multicolumn{3}{|c|}{ Voluntariness } \\
\hline $\begin{array}{l}\text { Voluntary } \\
\text { Part of work tasks } \\
\text { N/A }\end{array}$ & $\begin{array}{l}14 \\
9 \\
4\end{array}$ & $\begin{array}{l}51.9 \\
33.3 \\
14.8\end{array}$ \\
\hline
\end{tabular}


side after the pilot, with no statistically significant differences compared to pre-pilot: instrumental $(+1.20)$, experiential $(+0.70)$, and overall $(+1.00)$.

Moreover, we enquired about gamification (cf. Deterding, Dixon, Khaled, \& Nacke, 2011; Huotari \& Hamari, 2012; Kari, Piippo, Frank, Makkonen, \& Moilanen, 2016). More precisely, we enquired the participants' perceptions on a) adding gamified elements into the application or its usage and b) how it would influence their use. In general, the participants did not see much value in gamifying the application or its use. Rather, they perceived that gamification would not bring added value for them in this domain. It is to be noted that currently the application or its use did not involve any gamified elements.

\section{Expectations Towards the Application}

The key expectations the users had towards the use of the application before the implementation phase concerned ease of use, effortless use and adoption, strong authentication, trustworthiness and reliability, and ubiquitousness. Especially the ease of use and effortless use were emphasized. The application was also expected to manage their work-related communication needs as efficiently and fluently as comparable solutions for personal use (e.g., WhatsApp or Telegram) in varying environments.

Regarding the expectations on performance, it was expected that using the application would increase the security and privacy of confidential communication. Easy and fast use together with trustworthiness and reliability were considered to be particularly important performance expectations. In addition, the application was expected to be truly mobile, that is, to work in different countries, locations, and networks. Moreover, it was found that previous experience on using similar solutions influenced the performance expectations towards the implemented application. Previous experience had formed an image on such applications and their use on a general level, and this influenced the expectations regarding performance.

Regarding the expectations on effort, they were mainly based on the expectations that the application would be easy and effortless to use as well as easy to learn. In addition, easy implementation and no need for reading a user manual were expected. In terms of facilitating conditions, the technical and organizational infrastructure were expected to support the ease and effortlessness of use. Strong authentication was also seen as part of this. These were perceived crucial, and the confirmation of these expectations concerning effort and facilitating conditions was expected to promote the formation of the habit towards using the application.

Regarding expectations on social influence, they were largely based on other pilot participants and their behavior, mostly, how much they would use the application. The users expected to be able to test the application with other users and, if needed, to receive help and support for usage. Overall, the voluntariness of taking part in the pilot did not have influence on the user expectations, as the responses were very similar between the participants taking part in the pilot voluntary and the participants having it as a part of their work tasks.

\section{Experiences Affecting Continued Adoption and Discontinuance}

The continued adoption and discontinuance of the application was influenced by various types of use experiences during the implementation phase. Supporting the ECT, together with perceived performance, the use experiences that either positively or negatively (dis)confirmed the user expectations were of high importance in regard to satisfaction and subsequent (dis)continuance intention. Perceived performance was mostly viewed by the participants through how well the application functioned, how well it performed in different tasks, and how reliable and secure it was perceived to be. In practice, if the user perceived the application to be adequately easy to use, trustworthy, reliable, providing fluent communication (e.g., message delivery, quality of calls, cut offs), and exceeding the related expectations, it had a positive influence on the overall perceived 
performance and use experience with the application. This, in turn, promoted continued adoption. Contrary experiences promoted discontinuance.

The perceived advantage of using the application influenced continued adoption. A mere possibility to conduct secure communication with the application seemed to be inadequate for continued adoption of the application if the user was not aware or able to recognize the advantages over optional means of secure communication.

The users also expect and require experiences which concretely present that the use has been beneficial for oneself: In many cases, the personal benefit (e.g., how well it suited their personal work tasks, how easy and fast it was to use compared to other options) was valued more than the benefit to the organization. Nevertheless, the findings also highlight the importance of secure and reliable communication for safeguarding the organization. Relating to this, it was important for the users that the application enabled strong authentication, high level security for communication, and reliable message delivery. If the users had experiences that roused perceptions against this, it was likely to diminish satisfaction and promote discontinuance. Further, if the user did not have clear goals for the use before implementing the application, the perceived benefit was likely to be smaller, which promoted discontinuance during the implementation phase. This finding is something that concerns especially the implementation phase and is important for organizations to acknowledge.

In terms of the experiences relating specifically to effort, most important ones for continued adoption were those regarding ease of use, easiness to learn the use straight from the beginning, and perceiving that the use of the application was familiar from previous experiences with comparable applications. Regarding the experiences concerning the facilitating conditions, the most notable ones were those that concerned fluency in the application environment - partly containing similar aspect as perceived performance, strong authentication, and reliable technology as well as strictly negative experiences on technical issues, the application environment not working properly, and perceived lack of organizational level support towards the use. Experiences relating to social influence were mostly based on the activity of the other users, for example, how much they used the application. Additionally, specific usage tests with given tasks conducted during the pilot increased the perception that the application should be used. The formation of habit was endorsed by the use experiences concerning ease of use and relative advantage. Moreover, the ubiquitousness of the application, that is, whether or not it was perceived to be truly mobile and to work in varying environments, was imperative for habit formation. If the use did not provide satisfactory ease of use or sufficient relative advantage, it hindered the formation of habit. In general, positive use experiences regarding the aforementioned aspects influenced continued adoption positively. In contrast, negative use experiences promoted discontinuance.

\section{CONCLUSION}

The purpose of this exploratory study was to qualitatively examine what kinds of expectations users have towards mobile secure communication applications before the implementation phase and how the (dis)confirmation of the user expectations through use experiences during the implementation phase influences the continued adoption or discontinuance of the applications. The focus was on an organizational setting, on the use experiences, and on the continued adoption during the implementation phase.

The main research questions that the study aimed to answer were: 1 . What are the key expectations that users have towards mobile secure communication applications before the implementation phase? 2. How does the (dis)confirmation of these user expectations through the use experiences during the implementation phase influence the users' continued adoption or discontinuance of mobile secure communication applications? The main theoretical contribution follows from answering these two questions and the related findings. 
Regarding research question 1 , the key expectations the users had towards the use of the application before the implementation phase concerned ease of use, effortless use and adoption, trustworthiness and reliability, strong authentication, and ubiquitousness. The ease and effortlessness of use were especially highlighted, showing the importance of good usability. These results are in line with the innovation diffusion theory (Rogers, 2003) and also with the results of several previous studies, for example with those of Carlsson et al. (2006), who also note effort expectancy to affect mobile service use. In addition, previous experience with similar products forms an image of how the use is expected to be, which influences users' expectations towards the new product and subsequently the perceptions regarding the use experience.

Regarding research question 2 , the continued adoption of the application was influenced by various types of use experiences. The results support the ECT as the positive or negative (dis)confirmation of user expectations resulting from use experiences together with perceived performance are important for satisfaction and subsequent (behavioral) intention of continued adoption or discontinuance. In practice, if the user perceived the application to be adequately easy to use, secure and reliable, to work well in changing environments, and exceeding the related expectations, it promoted continued adoption. Also, the use feeling familiar with previous experiences was beneficial for continued adoption. Together with these, perceived performance in terms of flawless functioning and good performance of the application increased satisfaction and promoted continued adoption of the application. Discontinuance was promoted by contrary perceptions, for example, difficulties in using the application, bad functionality, errors during the use, and not meeting the expectations. Further, if the use of the application was not sufficiently goal-oriented, the perceived benefit of using it was likely to be smaller, which promoted discontinuance. Moreover, supporting prior research (e.g., Rogers, 2003), the perceived advantage of using the application influenced continued adoption. The UTAUT was used as a background for this qualitative study, and the presented findings regarding user expectations and use experiences influencing the adoption and use are mostly in line with the theory.

Previous studies (e.g., Koivisto, Makkonen, Frank, \& Riekkinen, 2016; Makkonen, Frank, \& Koivisto, 2017; Lee et al., 2015) stress the role of perceived usefulness affecting adoption and use, whereas our findings show that also personal benefit has a positive influence on mobile service use (dis)continuance in an organizational setting. Despite the overall attitude towards using the application being positive, a mere possibility to conduct mobile secure communication was not sufficient to maintain the interest towards the continued adoption of the application. This implies that the user must be able to acknowledge the goals and benefits of using the mobile secure communication application for continued adoption to take place.

\section{Practical Implications}

Considering the finding about attitude, it implies that the organizations should provide their employees with clear goals and meaning for using such applications. There are many potential ways to achieve this. However, with such applications, gamification is probably not a suitable way to approach goal-setting, as the participants did not see much value in gamifying the application or its use. One noteworthy finding was that even in an organizational setting and with such important tools as mobile secure communication applications, the perceived personal benefit of an individual user plays an important role in the continued adoption or discontinuance intention, at least if the decision is not forced by the organization. Therefore, the organizations should present their employees the benefits of the use not only from an organizational perspective but also from the user perspective.

Furthermore, as effortlessness and ease of use were highly emphasized in the findings, it is important to pay attention to usability also in the critical context of secure communication. Thus, the designers and providers of such solutions should focus on, in addition to reliable security and good functionality, making the solutions as easy to use and implement as possible. The providers would also benefit if their solutions would give a familiar feeling to the users already from the beginning. For example, in the case of mobile secure communication applications, the solutions would probably 
be better received if they would resemble popular and extensively used communication and instant messaging applications, such as WhatsApp, Slack, Telegram, or WeChat.

Further practical implications for advancing the diffusion of secure communication solutions are that their providers should not just market the resulting organizational benefits and deliver the solutions, but they should also support their client organizations in implementing the solutions into use. More precisely, the providers could offer their clients practical guidelines for the implementation, including also means to emphasize the individual end-user benefits. The client organizations could then market these individual benefits to their employees (i.e., the users of the solution) in order to make them convinced of the relative advantage of using the new solutions. Through increasing individual user acceptance, the organizations would also increase the acceptance in an organizational level and the use of the solutions among their employees, hence strengthening their IS security.

To conclude, this study contributes to the understanding of user expectations and use experiences with mobile secure communication applications. The findings and implications of this study benefit various actors operating in the IS security industry. The providers can benefit from the findings in developing better solutions and mobile applications for secure communication. The better products and services are likely to be adopted and diffused easier and, thus, rewarded by the market consisting of customers in the need of secure communication solutions. Additionally, the findings and implications can help relevant organizations in implementing secure communication solutions into their practices and disseminating those to their employees, subsequently improving the security and privacy of confidential communication.

\section{Limitations}

This study has three main limitations. First, although all the 50 pilot participants were invited to respond to the surveys, not everyone did this. However, as the focus was on open-ended questions and qualitative analysis, a sufficient amount of data (from 27 respondents) was gathered for the purpose of this study. Also, there were only five interviewees, but as the interviews were used as a secondary data source to complement the primary data and findings from the surveys, this is not seen as a limitation but rather the opposite. Second, implementing the application into use in the governmental organization was (at least at the beginning of the pilot) not yet decided for a long-term time scale but took place through a 12-week pilot period. However, the organization was actively looking for new solutions to support secure communication. Yet, this could have affected the use of the application among the users and how well the organization supported the use, as well as the eventual adoption of the application. However, being able to conduct the research in a real governmental organization provided a valuable research opportunity. Third, the general limitations of qualitative research need to be noted. However, in order to gain maximal benefit from using qualitative approach and avoid the potential problems and pitfalls, relevant guidelines for qualitative research were followed in planning and conducting the research (e.g., Braun \& Clarke, 2006; Guest et al., 2006; Myers, 2013; Myers \& Newman, 2007; Patton, 2002). It should also be noted that the themes identified in the thematic analysis are always based on the interpretations of the researchers (Guest et al., 2012). Therefore, relevant guidelines were also applied in doing the analysis. Typical for qualitative research is that it is difficult to make generalizations from the sample to a larger population (Myers, 2013) and one needs to be cautious if doing so. However, as a qualitative study, this research provides a more in-depth understanding on this specific context. Moreover, whilst the constructs such as effort expectancy and performance expectancy in the UTAUT are often used to refer to expectations during using the technology, they can also be used to guide investigations on and refer to expectations before the implementation of the technology, which was also the case in this exploratory study.

\section{Future Research}

The findings of this study also provide potential paths for future research. For example, whereas this study examined the user expectations, use experiences, and continued adoption of one specific 
mobile secure communication application, it would be interesting to investigate similar solutions at a more general level. Additionally, the target group could be restricted to certain kinds of users who have specific needs regarding their communication. As the study took place in a governmental organization, future studies could also be conducted in other types of organizations, or even in less formal environments, such as among individual users and in the case of personal use. Further, as gamification in the security domain and the related research are increasing (e.g., Furnell, Alotaibi \& Esmael, 2019), a potential topic for future research would be to investigate the influence of gamification on behavior in this setting with applications including specifically gamified elements. Moreover, researchers can also draw from our findings in their future research, for example, by building more comprehensive models and quantitatively testing them. 


\section{REFERENCES}

Baskerville, R. (1993). Information systems security design methods: Implications for information systems development. ACM Computing Surveys, 25(4), 375-414. doi:10.1145/162124.162127

Bates, W. S. (1970). Security of Computer-Based Information Systems. Datamation, 16(15), 60-65.

Bhattacherjee, A. (2001). Understanding information systems continuance: An expectation-confirmation model. Management Information Systems Quarterly, 25(3), 351-370. doi:10.2307/3250921

Braun, V., \& Clarke, V. (2006). Using thematic analysis in psychology. Qualitative Research in Psychology, 3(2), 77-101. doi:10.1191/1478088706qp063oa

Carlsson, C., Carlsson, J., Hyvönen, K., Puhakainen, J., \& Walden, P. (2006). Adoption of mobile devices/ services - searching for answers with the UTAUT. In Proceedings of the 39th Annual Hawaii International Conference on System Sciences, Hawaii (p. 132a). Academic Press.

Chan, K. L., Kwong, S., \& Longginnou, L. (1993). Security management on mobile-phone communication. In Proceedings of the IEEE Region 10 Conference on Computer, Communication, Control and Power Engineering 1993, Beijing, China (pp. 127-130). IEEE.

Cram, W. A., Proudfoot, J., \& D'Arcy, J. (2017). Seeing the forest and the trees: a meta-analysis of information security policy compliance literature. In Proceedings of the 50th Hawaii International Conference on System Sciences, Hawaii (pp. 4051-4060). Academic Press. doi:10.24251/HICSS.2017.489

Deterding, S., Dixon, D., Khaled, R., \& Nacke, L. (2011). From game design elements to gamefulness: defining gamification. In Proceedings of the 15th International Academic MindTrek Conference, Tampere, Finland (pp. 9-15). Academic Press. doi:10.1145/2181037.2181040

Dhillon, G., \& Backhouse, J. (2001). Current directions in IS security research: Towards socio-organizational perspectives. Information Systems Journal, 11(2), 127-153. doi:10.1046/j.1365-2575.2001.00099.x

Fishbein, M., \& Ajzen, I. (2010). Predicting and changing behavior: the reasoned action approach. New York, NY: Psychology Press.

Furnell, S., Alotaibi, F., \& Esmael, R. (2019). Aligning security practice with policy: guiding and nudging towards better behavior. In Proceedings of the 52nd Hawaii International Conference on System Sciences (pp. 5618-5627). Grand Wailea, Maui: University of Hawai'i at Manoa. doi:10.24251/HICSS.2019.676

Guest, G., Bunce, A., \& Johnson, L. (2006). How many interviews are enough? an experiment with data saturation and variability. Field Methods, 18(1), 59-82. doi:10.1177/1525822X05279903

Guest, G., MacQueen, K. M., \& Namey, E. E. (2012). Applied thematic analysis. Los Angeles, CA: SAGE. doi:10.4135/9781483384436

Guo, K. H. (2013). Security-related behavior in using information systems in the workplace: A review and synthesis. Computers \& Security, 32, 242-251. doi:10.1016/j.cose.2012.10.003

Huotari, K., \& Hamari, J. (2012). Defining gamification: a service marketing perspective. In Proceeding of the 16th international academic MindTrek conference, Tampere, Finland (pp. 17-22). ACM. doi:10.1145/2393132.2393137

Kari, T., Piippo, J., Frank, L., Makkonen, M., \& Moilanen, P. (2016). To gamify or not to gamify? gamification in exercise applications and its role in impacting exercise motivation. In Proceedings of the 29th Bled eConference "Digital economy" Research Volume, Bled, Slovenia, University of Maribor (pp. 393-405). Academic Press.

Kiwanuka, A. (2015). Acceptance process: The missing link between UTAUT and diffusion of innovation theory. American Journal of Information Systems, 3(2), 40-44.

Koivisto, K., Makkonen, M., Frank, L., \& Riekkinen, J. (2016). Extending the technology acceptance model with personal innovativeness and technology readiness: a comparison of three models. In Proceedings of the 29th Bled eConference "Digital economy" Research Volume, Bled, Slovenia, University of Maribor (pp. 113128). Academic Press. 
Lee, J., Hwang, C., \& Kwon, D. (2015). On the effect of perceived security, perceived privacy, perceived enjoyment, perceived interactivity on continual usage intention through perceived usefulness in mobile instant messenger for business. Journal of the Korea Society of Digital Industry and Information Management, 11(3), 159-177. doi:10.17662/ksdim.2015.11.3.159

Limayem, M., Hirt, S. G., \& Cheung, C. M. K. (2007). How habit limits the predictive power of intentions: The case of is continuance. Management Information Systems Quarterly, 31(4), 705-737. doi:10.2307/25148817

Makkonen, M., Frank, L., \& Koivisto, K. (2017). Age differences in technology readiness and its effects on information system acceptance and use: the case of online electricity services in Finland. In Proceedings of the 30th Bled eConference "Digital Transformation: From Connecting Things to Transforming Our Lives", Bled, Slovenia, University of Maribor (pp. 403-420). Academic Press. doi:10.18690/978-961-286-043-1.28

Mathieson, K. (1991). Predicting user intentions: Comparing the technology acceptance model with the theory of planned behavior. Information Systems Research, 2(3), 173-191. doi:10.1287/isre.2.3.173

Myers, M. D. (2013). Qualitative research in business and management (2nd ed.). Los Angeles, CA: SAGE.

Myers, M. D., \& Newman, M. (2007). The qualitative interview in IS research: Examining the craft. Information and Organization, 17(1), 2-26. doi:10.1016/j.infoandorg.2006.11.001

Oliver, R. L. (1977). Effect of expectation and disconfirmation on postexposure product evaluations - an alternative interpretation. The Journal of Applied Psychology, 62(4), 480-486. doi:10.1037/0021-9010.62.4.480

Oliver, R. L. (1980). A cognitive model of the antecedents and consequences of satisfaction decisions. JMR, Journal of Marketing Research, 17(4), 460-469. doi:10.1177/002224378001700405

Pahnila, S., Siponen, M., \& Zheng, X. (2011). Integrating habit into UTAUT: The Chinese eBay case. Pacific Asia Journal of the Association for Information Systems, 3(2), 1-30. doi:10.17705/1pais.03201

Patton, M. Q. (2002). Qualitative research \& evaluation methods (3rd ed.). Thousand Oaks, CA: SAGE.

Pham, H. C., Pham, D. D., Brennan, L., \& Richardson, J. (2017). Information security and people: A conundrum for compliance. AJIS. Australasian Journal of Information Systems, 21, 1-16. doi:10.3127/ajis.v21i0.1321

Rogers, E. M. (2003). Diffusion of Innovations (5th ed.). New York, NY: Free Press.

Siponen, M., \& Oinas-Kukkonen, H. (2007). A review of information security issues and respective research contributions. ACM SIGMIS Database: the DATABASE for Advances in Information Systems, 38(1), 60-80. doi:10.1145/1216218.1216224

Sommestad, T., Hallberg, J., Lundholm, K., \& Bengtsson, J. (2014). Variables influencing information security policy compliance: A systematic review of quantitative studies. Information Management \& Computer Security, 22(1), 42-75. doi:10.1108/IMCS-08-2012-0045

Soomro, Z. A., Shah, M. H., \& Ahmed, J. (2016). Information security management needs more holistic approach: A literature review. International Journal of Information Management, 36(2), 215-225. doi:10.1016/j. ijinfomgt.2015.11.009

Trend Micro Inc. (2017). In review: 2016's mobile threat landscape brings diversity, scale, and scope. Retrieved from https://blog.trendmicro.com/trendlabs-security-intelligence/2016-mobile-threat-landscape/

Venkatesh, V., Morris, M. G., Davis, G. B., \& Davis, F. D. (2003). User acceptance of information technology: Toward a unified view. Management Information Systems Quarterly, 27(3), 425-478. doi:10.2307/30036540

Venkatesh, V., Thong, J. Y., Chan, F. K., Hu, P. J. H., \& Brown, S. A. (2011). Extending the two-stage information systems continuance model: Incorporating UTAUT predictors and the role of context. Information Systems Journal, 21(6), 527-555. doi:10.1111/j.1365-2575.2011.00373.x

Venkatesh, V., Thong, J. Y., \& Xu, X. (2012). Consumer acceptance and use of information technology: Extending the unified theory of acceptance and use of technology. Management Information Systems Quarterly, 36(1), 157-178. doi: $10.2307 / 41410412$

Venkatesh, V., Thong, J. Y., \& Xu, X. (2016). Unified theory of acceptance and use of technology: A synthesis and the road ahead. Journal of the Association for Information Systems, 17(5), 328-376. doi:10.17705/1jais.00428 
Williams, M. D., Rana, N. P., \& Dwivedi, Y. K. (2012). A bibliometric analysis of articles citing the unified theory of acceptance and use of technology. In Y. K. Dwiwedi, R. M. Wade, \& S. L. Schneberger (Eds.), Information Systems Theory (pp. 37-62). New York, NY: Springer. doi:10.1007/978-1-4419-6108-2_3

Williams, M. D., Rana, N. P., \& Dwivedi, Y. K. (2015). The unified theory of acceptance and use of technology (UTAUT): A literature review. Journal of Enterprise Information Management, 28(3), 443-488. doi:10.1108/ JEIM-09-2014-0088

Willison, R., \& Siponen, M. (2007). A critical assessment of IS security research between 1990-2004. In Proceedings of the 15th European Conference on ISs. (pp. 1551-1559). St. Gallen, Switzerland: Copenhagen Business School.

\section{ENDNOTES}

An earlier - work-in-progress - version of this manuscript has been published as a research-in-progress paper in a conference. The authors hold all copyright for the previously published research-in-progress paper. Compared to the earlier work-in-progress version, first, this manuscript extends the introduction and background sections by extending the presentation of previous literature and presenting the theoretical background in more detail. Second, this manuscript provides a more comprehensive analysis and description of the findings, and also discusses them in more depth. Furthermore, completely new findings have been added, for example, regarding attitude. 


\section{APPENDIX A: THEMES OF THE PRE-IMPLEMENTATION SURVEY}

Table 2. Themes of the pre-implementation survey

\begin{tabular}{|l|l|l|}
\hline 1. Background & 1.1 Demographics & 1.2 Socioeconomic characteristics \\
\hline 2. Prior conditions & 2.1 Previous experience & 2.2 Previous practice \\
\hline $\begin{array}{l}\text { 3. Innovativeness, personality } \\
\text { variables }\end{array}$ & 4. Perceived voluntariness & 5. Performance expectations \\
\hline 6. Effort expectations & 7. Social aspects & 8. Facilitating conditions \\
\hline 9. Habit formation & 10. Usage & 11. Gamification \\
\hline
\end{tabular}

\section{APPENDIX B: THEMES OF THE POST-IMPLEMENTATION SURVEY}

Table 3. Themes of the post-implementation survey

\begin{tabular}{|l|l|l|}
\hline 1. Background & 1.1 Demographics & 1.2 Socioeconomic characteristics \\
\hline 2. Perceived voluntariness & 3. Performance experience & 4. Effort experience \\
\hline 5. Social aspects & 6. Facilitating conditions & 7. Habit formation \\
\hline 8. Usage & 9. (Dis)continuance & 10. Gamification \\
\hline
\end{tabular}

\section{APPENDIX C: THEMES OF THE INTERVIEWS}

Table 4. Themes of the interviews

\begin{tabular}{|l|l|l|}
\hline $\begin{array}{l}\text { Critical experiences during the } \\
\text { implementation }\end{array}$ & Use experiences & Feature specific functionality \\
\hline Issues promoting use & Issues hindering use & Experiences regarding the pilot \\
\hline
\end{tabular}


Tuomas Kari is a Postdoctoral Researcher (Information Systems Science) at the Institute for Advanced Management Systems Research (Turku, Finland). He also acts as a research fellow at the University of Jyväskylä, Finland. His topics of research include exergaming, wellness technology, self-tracking, information systems usage, user behaviour, and gamification. He has published, for example, in International Conference on Information Systems (ICIS), International Journal of Networking and Virtual Organizations, Journal of Virtual Worlds Research, and International Journal of Gaming and Computer-Mediated Simulations.

Markus Makkonen is a doctoral student at the Faculty of Information Technology, University of Jyväskylä, Finland. His research interests include the adoption and diffusion of information and communication technology (ICT) innovations, business models, business intelligence, and consumer behavior, especially in the context of electronic commerce, digital contents, as well as sports and wellness technologies. His research has been published in several information systems (IS) conferences and journals, such as the International Conference on Information Systems (ICIS), the European Conference on Information Systems (ECIS), and the Communications of the Association for Information Systems (CAIS).

Lauri Frank is a Senior Researcher of technology adoption at the Faculty of Information Technology at the University of Jyväskylä, and a docent of technology research at the Lappeenranta University of Technology. Frank's research focuses especially on the consumer behavior and business models of digital products and services.

Eeva Kettunen is a doctoral student at the University of Jyväskylä, Finland. Her main topic of research is digital coaching in the area of personal wellness. 